OPEN ACCESS

Edited by:

Keisuke Ito,

Albert Einstein College of

Medicine, United States

Reviewed by:

Rolf Marschalek,

Goethe University Frankfurt,

Germany

Barbara Buldini,

Dipartimento di Salute della

Donna e del Bambino, Italy

${ }^{*}$ Correspondence:

Lucio Hernán Castilla

lucio.castilla@umassmed.edu

Specialty section: This article was submitted to

Molecular and

Cellular Oncology,

a section of the journal

Frontiers in Oncology

Received: 25 October 2017

Accepted: 10 April 2018

Published: 26 April 2018

Citation:

Pulikkan JA and Castilla LH (2018)

Preleukemia and Leukemia-

Initiating Cell Activity in inv(16)

Acute Myeloid Leukemia.

Front. Oncol. 8:129.

doi: 10.3389/fonc.2018.00129

\section{Preleukemia and Leukemia-Initiating Cell Activity in inv(16) Acute Myeloid Leukemia}

\author{
John Anto Pulikkan and Lucio Hernán Castilla* \\ Department of Molecular, Cell and Cancer Biology, University of Massachusetts Medical School, Worcester, MA, \\ United States
}

Acute myeloid leukemia (AML) is a collection of hematologic malignancies with specific driver mutations that direct the pathology of the disease. The understanding of the origin and function of these mutations at early stages of transformation is critical to understand the etiology of the disease and for the design of effective therapies. The chromosome inversion inv(16) is thought to arise as a founding mutation in a hematopoietic stem cell (HSC) to produce preleukemic HSCs (preL-HSCs) with myeloid bias and differentiation block, and predisposed to AML. Studies in mice and human AML cells have established that inv(16) AML follows a clonal evolution model, in which preL-HSCs expressing the fusion protein $\mathrm{CBF} \beta-\mathrm{SMMHC}$ persist asymptomatic in the bone marrow. The emerging leukemia-initiating cells (LICS) are composed by the inv(16) and a heterogeneous set of mutations. In this review, we will discuss the current understanding of inv(16) preleukemia development, and the function of $\mathrm{CBF} \beta-\mathrm{SMMHC}$ related to preleukemia progression and LIC activity. We also discuss important open mechanistic questions in the etiology of inv(16) AML.

\footnotetext{
Keywords: myeloid, leukemia, CBFB-MYH11, CBF $\beta$-SMMHC, preleukemia, clonal evolution, leukemia-initiating cell, stem cells
}

\section{INTRODUCTION}

The core-binding factor (CBF) transcription factor has critical roles in hematopoietic stem cell (HSC) maintenance and differentiation by regulating expression of genes associated with cell fate decisions and proliferation in lymphoid and myeloid compartments (1). The CBF has two core subunits and is frequently associated with cofactors that modulate their activity or provide target specificity. The subunit CBF $\beta$ increases RUNX affinity to DNA approximately 40 -fold and stabilizes RUNX protein from proteasome degradation (2-4). The subunit RUNX (encoded by either RUNX1, RUNX2, and RUNX3 genes) binds to DNA at promoters and enhancers (consensus sequence TGYGGT). RUNX is the docking subunit that interacts with CBF $\beta$ and cofactors and has the nuclear localization signal $(5,6)$.

From the clinical and mechanistic points of view, AML is a collection of hematologic malignancies marked by specific driver mutations. RUNX1 and CBFB genes are recurrently mutated in AML. Although a variety of mutations in RUNX1 have been described in hematologic malignancies, the only rearrangement associated with $C B F B$ is the pericentric inversion inv(16)(p13q22), henceforth inv(16), in leukemia (7-9). The inv(16) generates the fusion gene CBFB-MYH11, encoding the leukemia fusion protein CBF $\beta-S M M H C$ (10). Most of inv(16) AML cases have a myelomonocytic morphology with abnormal eosinophils and are classified as AML subtype M4-Eo, 
and in rare occasions as AML subtypes M0, M1, M2, and M5 [French-American-British system (11)]. In spite of the morphology, the inv(16) AML transcriptome clusters as a single entity, suggesting a common underlying molecular alteration (12). The World Health Organization grouped "inv(16) AML" within the "AML with recurrent genetic abnormalities" based on genetic, molecular, and clinical features (13).

The name preleukemia has been used in different contexts in hematologic malignancies and has evolved in the past years (14). The preleukemic HSCs (preL-HSCs) can be considered as HSCs with inv(16) as a founding mutation that generate a clonal expansion of myeloid progenitor cells primed for leukemia (15). In this review, we summarize the current understanding in preleukemia progression of inv(16) AML.

\section{CBF $\beta$-SMMHC DOMAINS THAT REGULATE LEUKEMIA DEVELOPMENT}

Two domains in CBF $\beta$-SMMHC that are critical for its leukemogenic function: the RUNX binding domain (RBD) and the assembly competence domain (ACD) (Figure 1). The RBD, corresponding to the $135 \mathrm{~N}$-terminal amino acids of $\mathrm{CBF} \beta$ region at the $\mathrm{N}$-terminus of the fusion protein, binds to the RUNX factors $(16,17)$. Genetic evidence, using $C b f b^{+/ M Y H 11}$ knock-in mice, revealed that RUNX activity is essential for CBF $\beta-S M M H C$ associated leukemia function. Accordingly, reduction of Runx1 or Runx2 expression inhibited CBF $\beta$-SMMHC-mediated differentiation block in embryos and leukemia onset in mice $(18,19)$. Furthermore, the increase in Runx2 levels reduced leukemia median latency (20). RUNX1 also interacts with the high-affinity binding domain (HABD), at the N-terminus of SMMHC. Surprisingly, RUNX1 binds to CBF $\beta-S M M H C$ with approximately 10 -fold higher affinity to than to $\mathrm{CBF} \beta$. Its dual interaction with the $\mathrm{RBD}$ and $\mathrm{HABD}$ provides a rationale for the observed dominant negative function of the fusion protein outcompeting CBF $\beta$ for RUNX1 binding (21). A later study using $C b f b^{+/ M Y H 11 d 179-221}$ knock-in mice expressing $C B F \beta-$ SMMHC lacking the HABD established that HABD regulates myeloid differentiation induced by $\mathrm{CBF} \beta-\mathrm{SMMHC}$ but it may actually inhibit leukemia by altering the LIC pool (22). These findings have direct clinical significance because although the majority of inv(16) AML cases include HABD sequence in the

\begin{tabular}{cr}
$\mathrm{CBF} \beta$ & \multicolumn{2}{c}{ SMMHC } \\
\hline RBD & ACD \\
\hline RUNX1 binding & $\begin{array}{r}\text { oligomerization } \\
\text { HDAC8 binding }\end{array}$
\end{tabular}

FIGURE 1 | Protein organization of $\mathrm{CBF} \beta-\mathrm{SMMHC}$. Schematic representation of the $\mathrm{CBF} \beta-\mathrm{SMMHC}$ fusion protein, including the RUNX1binding domain (RBD) at the $\mathrm{N}$-terminus of $\mathrm{CBF} \beta$, the high-affinity binding domain (HABD) at the proximal end of SMMHC, and the assembly competence domain (ACD) near the C-terminus in the SMMHC region. Functional regions are marked with dash line at the bottom.
CBFB-MYH11 transcripts, fraction of cases lack HABD sequence due to a different breakpoint on the MYH11 part of inv(16). The 28 amino acid ACD near the $\mathrm{C}$-terminus is responsible for the oligomerization of $\mathrm{CBF} \beta-\mathrm{SMMHC}$ molecules and formation of filament structures (23-25). The ACD activity is needed for CBF $\beta$-SMMHC's ability to inhibit myeloid differentiation, regulate the expression of $\mathrm{CBF}$ targets, and to reduce cell cycle and its nuclear localization in vitro $(26,27)$. Two recent studies using different inv(16) leukemia models have established that the ACD is essential for the expansion of preleukemic cells and for leukemia development $(28,29)$. Furthermore, the analysis of preleukemic progenitor cells revealed that ACD activity is critical for block in early B-cell differentiation but that sequences outside the ACD in the fusion protein impair T-cell differentiation. Finally, the C-terminal 95 amino acid region of $\mathrm{CBF} \beta-\mathrm{SMMHC}$, which includes the $\mathrm{ACD}$, binds to the histone deacetylase $\operatorname{HDAC} 8(30,31)$. This interaction is essential for the inv(16) LIC activity because HDAC8 deacetylates p53, rendering it inactive, and modulates the transcription repression function of the fusion protein (31). Finally, inhibition of $\mathrm{CBF} \beta-\mathrm{SMMHC}$ binding to these factors may efficiently reduce preL-HSC and LIC activities, resulting in promising candidates for targeted therapies (32).

\section{THE ORIGIN OF inv(16) PRELEUKEMIA}

Our understanding on the origin of AML is still evolving, and in general terms it seems to follow a clonal evolution model (33-35). In inv(16) AML, a small number of studies have tested the origin of inv(16) preL-HSCs in the hematopoietic system. Studies using a breakpoint backtracking approach evaluated whether the inv(16) breakpoint identified in the DNA of a patient's inv(16) AML sample is present in the patient's neonatal bloodspot (also called Guthrie card or neonatal heel prick). Two studies identified the inv(16) breakpoint in the bloodspots, demonstrating that preL-HSCs can originate during fetal development and persist quiescent for years (4 to 10 in these studies) before AML diagnosis $(36,37)$. In a third case with inv(16) AML, the bloodspot analysis was negative suggesting that either the preL-HSCs were infrequent (below the sensitivity of the assay) or that inv(16) occurred postnatally. Of note, since backtracking studies have only been done in pediatric $\operatorname{inv}(16)$ AML cases, it is unknown if inv(16) preL-HSCs are prenatal in adult AML. Breakpoint backtracking studies for other leukemia fusion genes, such as RUNX1-RUNX1T1 and TEL-RUNX1, have also confirmed the prenatal origin of preLHSCs (38-40).

The screening of leukemia fusion transcripts using RT-PCR analysis in healthy individuals revealed that 1 of 10 cord blood and 1 of 58 peripheral blood samples from adult individuals were $C B F B-M Y H 11$ positive (41). These results lack statistical value due to the reduced sample size but suggest that preL-HSCs may persist in the hematopoietic system for years. However, the use of RT-PCR has been disputed because of the challenge in identifying the chromosome breakpoints in fusion transcript positive samples of healthy individuals $(42,43)$, result that could be explained by transplicing $(44,45)$. 


\section{THE inv(16) PRELEUKEMIC PROGRESSION}

The identification of inv(16) preL-HSCs and progenitor cells has important therapeutic value because it is considered the source of leukemia development, drug resistance, and relapse. From a conceptual point, it would shed light on the etiology of disease progression. Studies in mice where allelic CBFB-MYH11 expression is activated in hematopoietic cells have established that leukemia is preceded by a preleukemic period of 4 to 6 months, and the median leukemia latency can be delayed or render incomplete penetrance by reducing the number of HSCs expressing CBFB-MYH11 $(28,46)$. Furthermore, chimeric mice (composed by $C b f b^{M Y H 11 /+}$ embryonic stem cells and wild-type blastocyst cells) expressing CBFB-MYH11 in a fraction of their HSCs remained healthy and only developed AML when treated with chemical or retroviral mutagenesis $(20,47)$. These studies determined that $C B F B-M Y H 11$ expression is necessary but not sufficient for leukemogenesis.

During the preleukemic period, Cbfb $b^{M Y H 11 /+}$ HSCs produce abnormal hematopoiesis, with cell compartment-specific defects, myeloid bias, and multilineage differentiation block (Figure 2). In the early progenitor compartment, CBF $\beta-S M M H C$ expression induces expansion of the short-term HSCs and multipotential

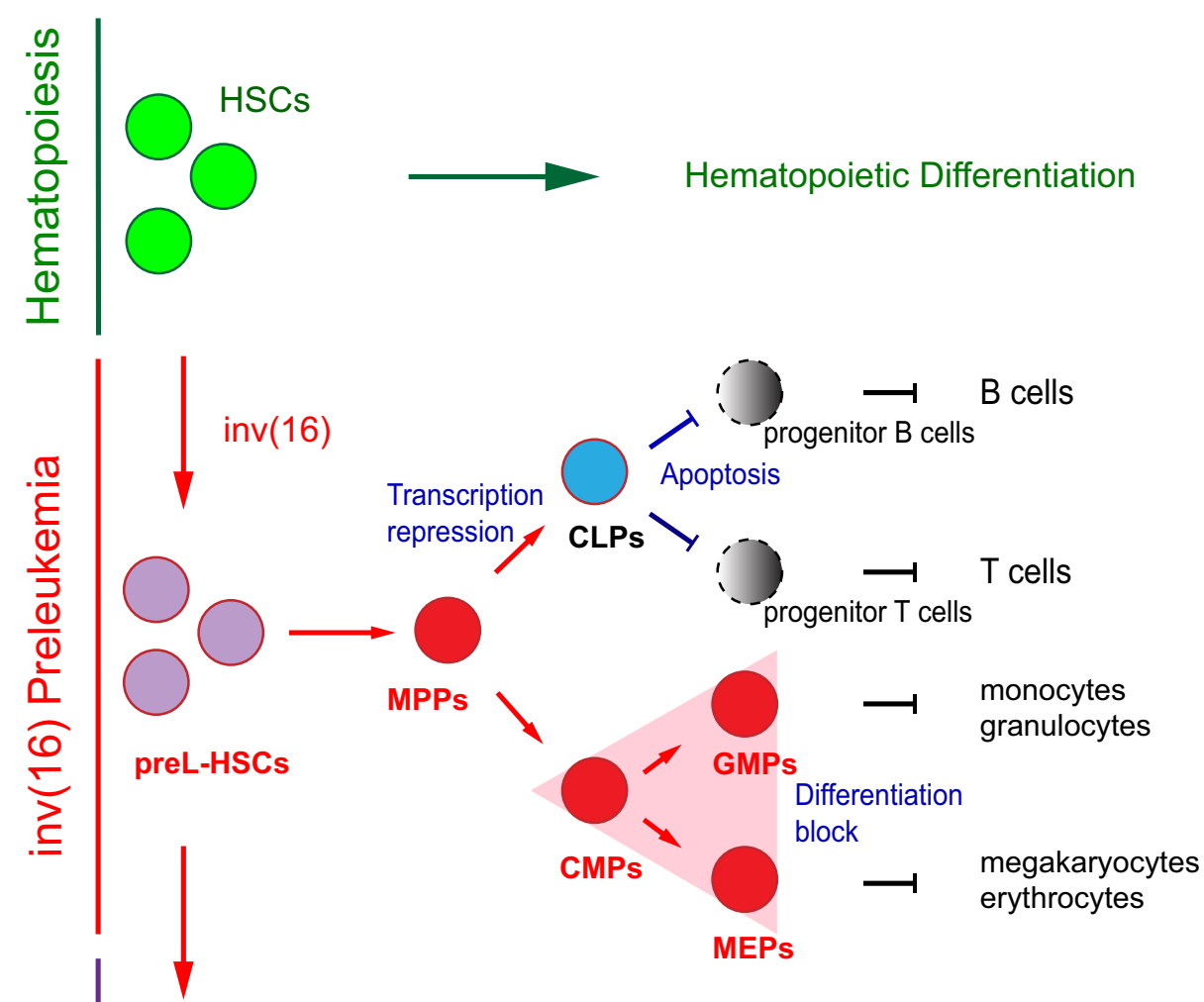

Cooperating Mutations

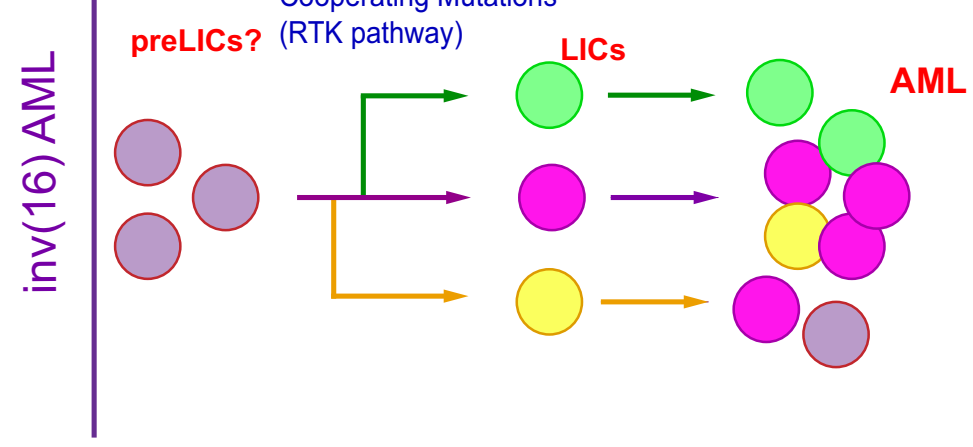

FIGURE 2 | Model of inv(16) associated preleukemia. Normal hematopoiesis is summarized on top. Preleukemia hematopoietic stem cell (preL-HSCs) with inv(16) and myeloid preleukemic progenitors (triangle compartment) are shown in red; preL-HSC-derived lymphoid progenitors and lineages with differentiation block are depicted in gray. Clonal expansion of leukemic cells from a putative preleukemia initiating cell with inv(16) and "cooperating" mutations are shown in green, violet, and orange. 
progenitor (MPP) cells, although the frequency of long-term HSCs (putative preLICs) is unchanged, indicating that CBF $\beta$ SMMHC may modulate factors associated with cell-fate decisions $(46,48)$.

These HSCs undergo normal early lymphoid differentiation, with normal numbers of common lymphoid progenitors (CLPs) but with reduced expression of transcription factors ( $E b f, E 2 a$, and Pax5) responsible for the commitment to $\mathrm{B}$ and $\mathrm{T}$ cell differentiation (49). During B cell commitment, CBF $\beta-S M M H C$ induces a marked reduction in pre-pro $B$ cells and in pre-B cells due to apoptosis. These blocks are probably due to repression of RUNX1 activity because similar deficiencies were reported in Cbfb- and Runx1-knockout mice (50-52). Similarly, differentiation of CBF $\beta$-SMMHC-expressing CLPs to T cell progenitors showed reduced cell number and viability of the double-negative compartments (53). Its repressive function in the production of lymphoid cells in humans was confirmed by fluorescent in situ hybridization analysis of lineage sorted inv(16) AML cells (54). Interestingly, the inability of $\operatorname{inv}(16)$ preL-HSCs to differentiate to $\mathrm{B}$ and $\mathrm{T}$ cells provides a mechanism for the myeloid leukemia bias observed in inv(16) AML.

CBF $\beta$-SMMHC-expressing preL-HSCs undergo partial myeloid differentiation, displaying a mixed myeloid-erythroid progenitors (MEPs) and common myeloid progenitors (CMPs) immunophenotype [Figure 2, red triangle (46)] and a predominant blast/myeloblast and promyelocyte morphology. Contrary to its strong apoptotic activity on the lymphoid compartment, CBF $\beta-S M M H C$ increases the viability of preleukemic myeloid cells and enhances their resistance to genotoxic stress $(46,48,55)$. The mechanism by which CBF $\beta-S M M H C$ blocks myeloid differentiation is not fully understood. Expression studies suggest that levels of a number of myeloid factors are affected by the fusion protein, including the repression of transcription factors that regulate myeloid lineage commitment (e.g., Cebpa, PU.1, Sox4, Hoxa9, and Irf8), some of which are known Runx1 targets. On the other hand, upregulated factors in preleukemic myeloid cells are implicated in survival and proliferation pathways [e.g., Csf2rb, il1rl1, Fosb, c-Jun, Erg1, and WT1 (28, 55, 56)]. Despite significant progress in this area, it is not clear which of these targets directs differentiation block in inv(16) AML. For example, the myeloid transcription factors $\mathrm{C} / \mathrm{EBP} \alpha$ and PU.1, both CBF targets, act as tumor suppressors in AML (57-59). In addition, Sox 4 has been shown to function as an oncogene in Cebpa-mutated AML (60). On the other hand, expression of the colony stimulating factor 2 receptor beta (Csf2rb), is expressed in myeloid progenitor cells of $C b f b^{56 M /+} ; M x 1 C r e$ mice and has a negative correlation with preL-HSC activity (56).

Transplantation studies of inv(16) preleukemic myeloid cells in mice, revealed that preleukemic cells could not induce leukemia in irradiated recipients $(28,46)$, indicating that preL-HSCs are not LICs, and that "cooperating" mutations are needed for leukemia transformation. Alternatively, the LIC activity is possibly present at a frequency below 1 in 20,000 preleukemic cells. Therefore, as rare preL-HSCs differentiate to myelomonocytic preleukemic cells and accumulate in the MEP/GMP compartment, additional events seem to be required for leukemia transformation.

\section{LIC ACTIVITY IN inv(16) AML}

Our understanding of LIC activity is evolving rapidly with the application of new technologies. Using targeted sequencing techniques in diagnostic inv(16) AML samples, studies have identified an average of 3 (range $=0-6$ ) secondary mutations per sample $(61,62)$. The majority of inv(16) AML "cooperating" mutations are in genes encoding components of the RTK pathway, with predominance KIT, FLT3, and NRAS (63-65). In contrast, mutations in genes associated with components of cohesin or chromatin complexes are rare $(62,66)$. Evidence for inv(16) and PU.1 associated leukemia in mice suggests that transformation of preleukemic progenitors could be enhanced by mutations that "weaken" its oncogenic repression activity, thereby moving the differentiation block to a more mature myeloid progenitor that is permissive for transformation $(22,67)$. This model has been previously illustrated using mouse models for CEBPA-mutated AML. Cebpa-null mice show differentiation block at the CMPs and remain leukemia free. However, in mice carrying a leukemiaassociated Cebpa point mutation, differentiation continues to stall at the committed myeloid progenitors and mice succumb with myeloid leukemia $(68,69)$. The molecular mechanism underlying this perplexing function, however, remains unknown.

inv(16) AML follows the clonal evolution model, whereby de novo inv(16) AML samples at diagnosis are composed of multiple leukemia subclones, which have emerged from the same preL-HSCs (Figure 2). The subclones share the founding mutation but have a different combination of "cooperating" mutations (70). Each subclone originates from an independent LIC with a different mutation combination and sensitivity to therapies. In addition to the leukemia subclones, the de novo AML sample includes preL-HSCs with reduced chemosensitivity, and that may serve as precursors for the expansion of resistant clones at relapse $(15,71)$. Longitudinal (diagnosis/ relapse-matched) studies of AML mutational landscape using whole-genome sequencing have confirmed the clonal evolution model in inv(16) AML $(72,73)$. In these studies, the AML samples contained 1 to 18 "cooperating" mutations ( mean $=6$ ), corresponding to 1 to 3 mutations per subclone. In addition, inv(16) was found in all subclones at both stages of disease progression while a heterogeneity in the "cooperating" mutations indicated clonal evolution and differential sensitivity to therapy. Studies in mice have validated the basic premise of this model in inv(16) AML $(48,74,75)$, and the weak LIC activity reported in human and mouse studies was validated in titration dilution transplantation experiments (48).

\section{inv(16) AS A "COOPERATING” MUTATION IN LEUKEMIA}

The $\operatorname{inv}(16)$ is predominantly a founding mutation that predisposes to de novo AML. Accumulating case reports have identified inv(16) in other hematologic malignancies clearly showing that this inversion, at a low frequency, can also originate as a "cooperating" mutation in the progression of other cancers. The inv(16) can emerge in BCR-ABL-positive chronic myelogenous leukemia 
(CML) cases transitioning to blast crisis (76-80). The appearance of a inv(16)-positive predominant clone is accompanied by a switch to an immature monocytic morphology and dysplastic eosinophils. In CML cells, the occurrence of inv(16) predicts rapid evolution and poor outcome $(77,80)$. In addition, inv(16) has been reported in 1-2\% of tAML cases that progressed from MDS or solid tumors (81). Probably due to the paucity of these cases, the mechanism of CBF $\beta$-SMMHC function in the LICs from CML-PB or tAML cases has not been studied. However, the understanding of its function when acting as a "cooperating" mutation could open new insights on leukemia progression. It should be noted that CBF $\beta$-SMMHC function in the LIC of CML-chronic phase (i.e., with active proliferative signals) or post-therapy HSCs/MDS (i.e., with higher mutation content) may involve different targets.

\section{CONCLUSION AND PERSPECTIVES}

The inv(16) is a somatic mutation that activates CBF $\beta-S M M H C$ expression in an HSC, either in utero or after birth. Indirect evidence suggests that these preL-HSCs can perdure for years to produce a clonal population with myeloid bias and impaired differentiation. Over time, the preL-HSCs are primed for leukemogenesis after acquiring a relatively small number of "cooperating" mutations, predominantly in components of the RTK pathway. The finding that mutations in genes associated with epigenetic complexes, frequently mutated in other AMLs, are practically absent in inv(16) AML suggests that CBF $\beta-S M M H C$ function may deregulate chromatin dynamics.

Future studies are endowed to demonstrate whether preLHSCs can produce preleukemia initiating cells in inv(16) AML (Figure 2). The application of new technologies, such as single cell analysis, next-generation sequencing, CRISPR/Cas9 editing in primary hematopoietic stem and progenitor cells, pharmacology, and sophisticated animal models will greatly enhance our understanding of inv(16) preleukemia biology and minimal residual disease. Considering that each LIC in diagnostic inv(16) AML has a small number of mutations and a heterogeneity of mutations between diagnosis and relapse cases, targeted therapies inhibiting CBF $\beta$-SMMHC binding to RUNX1 and HDAC8, and combination with RTK inhibitors may result in effective treatment. Pharmacologic approaches directly inhibiting specific signals could be valuable to define which components drive

\section{REFERENCES}

1. Wang CQ, Mok MM, Yokomizo T, Tergaonkar V, Osato M. Runx family genes in tissue stem cell dynamics. Adv Exp Med Biol (2017) 962:117-38. doi:10.1007/978-981-10-3233-2_9

2. Gu TL, Goetz TL, Graves BJ, Speck NA. Auto-inhibition and partner proteins, core-binding factor beta (CBFbeta) and Ets-1, modulate DNA binding by CBFalpha2 (AML1). Mol Cell Biol (2000) 20:91-103. doi:10.1128/MCB.20. 1.91-103.2000

3. Tang YY, Crute BE, Kelley JJ, Huang X, Yan J, Shi J, et al. Biophysical characterization of interactions between the core binding factor alpha and beta subunits and DNA. FEBS Lett (2000) 470:167-72. doi:10.1016/S0014-5793(00)01312-0

4. Tang YY, Shi J, Zhang L, Davis A, Bravo J, Warren AJ, et al. Energetic and functional contribution of residues in the core binding factor beta (CBFbeta) preleukemia to leukemia progression. In addition, little is known on the preL-HSC activity in relation with the microenvironment and how changes in the immune system affect LIC activity. The role of RUNX1 in inv(16) AML seems perplexing, as reduction in Runx1 levels decreases leukemia development in mice but loss of RUNX1 levels induce cell death in inv(16) AML cells. It is, therefore, possible that reduction in RUNX1 levels may be required for preleukemia formation and transition to LICs. New strategies designed to force increase in RUNX1 expression may help define new RUNX targets with potential antileukemia functions. The dependence of the RBD and ACD domains in CBF $\beta$-SMMHC in preleukemia and LIC activity clearly indicate that SMMHC-multimerization and RUNX1 binding are critical leukemogenic functions. Interestingly, mutations in both domains interfere with the nuclear localization of the fusion protein. Hence, the development of strategies to directly interfere with the nuclear import of CBF $\beta$-SMMHC may abrogate its leukemic activity. Finally, the study of the inv(16) LIC activity in de novo AML versus tAML and CML-blast crisis may shed mechanistic insights on the function of the fusion protein in cells with different mutation composition and proliferation capacity.

\section{AUTHOR CONTRIBUTIONS}

All authors listed have contributed to the preparation and editing of the work and approved it for publication.

\section{ACKNOWLEDGMENTS}

The authors thank the members of the Castilla laboratory for their comments and discussions on preleukemia progression and leukemia-initiating cell activity in core-binding factor leukemia. A number of original articles had to be omitted due to space limitations.

\section{FUNDING}

LC was supported by a grant from NIH (R01 CA204979) and a Translational Research Program grant from the Leukemia \& Lymphoma Society (6364-15). JP was funded by a Scholar Award from American Society of Hematology, Young Investigator Award from Alex's Lemonade Stand Foundation for Childhood Cancer, and a Discovery Grant from Lauri Strauss Leukemia Foundation.

subunit to heterodimerization with CBFalpha. J Biol Chem (2000) 275: 39579-88. doi:10.1074/jbc.M007350200

5. Kamachi Y, Ogawa E, Asano M, Ishida S, Murakami Y, Satake M, et al. Purification of a mouse nuclear factor that binds to both the A and B cores of the polyomavirus enhancer. J Virol (1990) 64:4808-19.

6. Ogawa E, Inuzuka M, Maruyama M, Satake M, Naito-Fujimoto M, Ito Y, et al. Molecular cloning and characterization of PEBP2 beta, the heterodimeric partner of a novel Drosophila runt-related DNA binding protein PEBP2 alpha. Virology (1993) 194:314-31. doi:10.1006/viro.1993.1262

7. Hyde RK, Liu P, Friedman AD. RUNX1 and CBFbeta mutations and activities of their wild-type alleles in AML. Adv Exp Med Biol (2017) 962:265-82. doi:10.1007/978-981-10-3233-2_17

8. Le Beau MM, Larson RA, Bitter MA, Vardiman JW, Golomb HM, Rowley JD. Association of an inversion of chromosome 16 with abnormal marrow 
eosinophils in acute myelomonocytic leukemia. A unique cytogeneticclinicopathological association. N Engl J Med (1983) 309:630-6. doi:10.1056/ NEJM198309153091103

9. Metzeler KH, Bloomfield CD. Clinical relevance of RUNX1 and CBFB alterations in acute myeloid leukemia and other hematological disorders. Adv Exp Med Biol (2017) 962:175-99. doi:10.1007/978-981-10-3233-2_12

10. Liu P, Tarle SA, Hajra A, Claxton DF, Marlton P, Freedman M, et al. Fusion between transcription factor CBF beta/PEBP2 beta and a myosin heavy chain in acute myeloid leukemia. Science (1993) 261:1041-4. doi:10.1126/ science. 8351518

11. Bennett JM, Catovsky D, Daniel MT, Flandrin G, Galton DA, Gralnick HR, et al. Proposals for the classification of the acute leukaemias. FrenchAmerican-British (FAB) co-operative group. Br J Haematol (1976) 33:451-8. doi:10.1111/j.1365-2141.1976.tb03563.x

12. Valk PJ, Verhaak RG, Beijen MA, Erpelinck CA, Barjesteh van Waalwijk van Doorn-Khosrovani S, Boer JM, et al. Prognostically useful gene-expression profiles in acute myeloid leukemia. N Engl J Med (2004) 350:1617-28. doi:10.1056/ NEJMoa040465

13. Swerdlow SH, Campo E, Harris NL, Jaffe ES, Pileri SA, Stein H, et al. WHO classification of tumours of haematopoietic and lymphoid tissues. In: OMS, editor. WHO Classification of Tumours of Haematopoietic and Lymphoid Tissues. France: World Health Organization (2008). 439 p.

14. Koeffler HP, Leong G. Preleukemia: one name, many meanings. Leukemia (2017) 31:534-42. doi:10.1038/leu.2016.364

15. Corces-Zimmerman MR, Hong WJ, Weissman IL, Medeiros BC, Majeti R. Preleukemic mutations in human acute myeloid leukemia affect epigenetic regulators and persist in remission. Proc Natl Acad Sci U S A (2014) 111: 2548-53. doi:10.1073/pnas.1324297111

16. Goger M, Gupta V, Kim WY, Shigesada K, Ito Y, Werner MH. Molecular insights into PEBP2/CBF beta-SMMHC associated acute leukemia revealed from the structure of PEBP2/CBF beta. Nat Struct Biol (1999) 6:620-3. doi:10.1038/10664

17. Huang X, Peng JW, Speck NA, Bushweller JH. Solution structure of core binding factor beta and map of the CBF alpha binding site. Nat Struct Biol (1999) 6:624-7. doi:10.1038/10670

18. Hyde RK, Zhao L, Alemu L, Liu PP. Runx1 is required for hematopoietic defects and leukemogenesis in Cbfb-MYH11 knock-in mice. Leukemia (2015) 29:1771-8. doi:10.1038/leu.2015.58

19. Kuo YH, Zaidi SK, Gornostaeva S, Komori T, Stein GS, Castilla LH. Runx2 induces acute myeloid leukemia in cooperation with Cbfbeta-SMMHC in mice. Blood (2009) 113:3323-32. doi:10.1182/blood-2008-06-162248

20. Castilla LH, Perrat P, Martinez NJ, Landrette SF, Keys R, Oikemus S, et al. Identification of genes that synergize with Cbfb-MYH11 in the pathogenesis of acute myeloid leukemia. Proc Natl Acad Sci U S A (2004) 101:4924-9. doi:10.1073/pnas.0400930101

21. Lukasik SM, Zhang L, Corpora T, Tomanicek S, Li Y, Kundu M, et al. Altered affinity of CBF beta-SMMHC for Runx1 explains its role in leukemogenesis. Nat Struct Biol (2002) 9:674-9. doi:10.1038/nsb831

22. Kamikubo Y, Zhao L, Wunderlich M, Corpora T, Hyde RK, Paul TA, et al. Accelerated leukemogenesis by truncated CBF beta-SMMHC defective in high-affinity binding with RUNX1. Cancer Cell (2010) 17:455-68. doi:10.1016/j. ccr.2010.03.022

23. Ikebe M, Komatsu S, Woodhead JL, Mabuchi K, Ikebe R, Saito J, et al. The tip of the coiled-coil rod determines the filament formation of smooth muscle and nonmuscle myosin. J Biol Chem (2001) 276:30293-300. doi:10.1074/ jbc.M101969200

24. Sohn RL, Vikstrom KL, Strauss M, Cohen C, Szent-Gyorgyi AG, Leinwand LA. A 29 residue region of the sarcomeric myosin rod is necessary for filament formation. J Mol Biol (1997) 266:317-30. doi:10.1006/jmbi.1996.0790

25. Zhang L, D'Costa J, Kummalue T, Civin CI, Friedman AD. Identification of a region on the outer surface of the CBFbeta-SMMHC myeloid oncoprotein assembly competence domain critical for multimerization. Oncogene (2006) 25:7289-96. doi:10.1038/sj.onc.1209725

26. D'Costa J, Chaudhuri S, Civin CI, Friedman AD. CBFbeta-SMMHC slows proliferation of primary murine and human myeloid progenitors. Leukemia (2005) 19:921-9. doi:10.1038/sj.leu.2403755

27. Kummalue T, Lou J, Friedman AD. Multimerization via its myosin domain facilitates nuclear localization and inhibition of core binding factor (CBF) activities by the CBFbeta-smooth muscle myosin heavy chain myeloid leukemia oncoprotein. Mol Cell Biol (2002) 22:8278-91. doi:10.1128/MCB.22. 23.8278-8291.2002

28. Kim HG, LeGrand J, Swindle CS, Nick HJ, Oster RA, Chen D, et al. The assembly competence domain is essential for inv(16)-associated acute myeloid leukemia. Leukemia (2017) 31(10):2267-71. doi:10.1038/leu.2017.236

29. Zhao L, Alkadi H, Kwon EM, Zhen T, Lichtenberg J, Alemu L, et al. The C-terminal multimerization domain is essential for leukemia development by CBFbeta-SMMHC in a mouse knockin model. Leukemia (2017) 31(12): 2841-4. doi:10.1038/leu.2017.262

30. Durst KL, Lutterbach B, Kummalue T, Friedman AD, Hiebert SW. The $\operatorname{inv}(16)$ fusion protein associates with corepressors via a smooth muscle myosin heavy-chain domain. Mol Cell Biol (2003) 23:607-19. doi:10.1128/ MCB.23.2.607-619.2003

31. Qi J, Singh S, Hua WK, Cai Q, Chao SW, Li L, et al. HDAC8 inhibition specifically targets $\operatorname{Inv}(16)$ acute myeloid leukemic stem cells by restoring p53 acetylation. Cell Stem Cell (2015) 17:597-610. doi:10.1016/j.stem.2015. 08.004

32. Richter L, Wang Y, Hyde RK. Targeting binding partners of the CBFbetaSMMHC fusion protein for the treatment of inversion 16 acute myeloid leukemia. Oncotarget (2016) 7:66255-66. doi:10.18632/oncotarget.11357

33. Ley TJ, Ding L, Walter MJ, McLellan MD, Lamprecht T, Larson DE, et al. DNMT3A mutations in acute myeloid leukemia. $N$ Engl J Med (2010) 363: 2424-33. doi:10.1056/NEJMoa1005143

34. Ley TJ, Mardis ER, Ding L, Fulton B, McLellan MD, Chen K, et al. DNA sequencing of a cytogenetically normal acute myeloid leukaemia genome. Nature (2008) 456:66-72. doi:10.1038/nature07485

35. Mardis ER, Ding L, Dooling DJ, Larson DE, McLellan MD, Chen K, et al. Recurring mutations found by sequencing an acute myeloid leukemia genome. N Engl J Med (2009) 361:1058-66. doi:10.1056/NEJMoa0903840

36. McHale CM, Wiemels JL, Zhang L, Ma X, Buffler PA, Feusner J, et al. Prenatal origin of childhood acute myeloid leukemias harboring chromosomal rearrangements $\mathrm{t}(15 ; 17)$ and inv(16). Blood (2003) 101:4640-1. doi:10.1182/ blood-2003-01-0313

37. Poddighe PJ, Veening MA, Mansur MB, Loonen AH, Westers TM, Merle PA, et al. A novel cryptic CBFB-MYH11 gene fusion present at birth leading to acute myeloid leukemia and allowing molecular monitoring for minimal residual disease. Hum Pathol (2018) 11:34-8. doi:10.1016/j.ehpc.2017.09.001

38. Wiemels JL, Cazzaniga G, Daniotti M, Eden OB, Addison GM, Masera G, et al. Prenatal origin of acute lymphoblastic leukaemia in children. Lancet (1999) 354:1499-503. doi:10.1016/S0140-6736(99)09403-9

39. Wiemels JL, Ford AM, Van Wering ER, Postma A, Greaves M. Protracted and variable latency of acute lymphoblastic leukemia after TEL-AML1 gene fusion in utero. Blood (1999) 94:1057-62.

40. Wiemels JL, Xiao Z, Buffler PA, Maia AT, Ma X, Dicks BM, et al. In utero origin of $\mathrm{t}(8 ; 21)$ AML1-ETO translocations in childhood acute myeloid leukemia. Blood (2002) 99:3801-5. doi:10.1182/blood.V99.10.3801

41. Song J, Mercer D, Hu X, Liu H, Li MM. Common leukemia- and lymphomaassociated genetic aberrations in healthy individuals. J Mol Diagn (2011) 13: 213-9. doi:10.1016/j.jmoldx.2010.10.009

42. Marcucci G, Strout MP, Bloomfield CD, Caligiuri MA. Detection of unique ALL1 (MLL) fusion transcripts in normal human bone marrow and blood: distinct origin of normal versus leukemic ALL1 fusion transcripts. Cancer Res (1998) 58:790-3.

43. Uckun FM, Herman-Hatten K, Crotty ML, Sensel MG, Sather HN, TuelAhlgren L, et al. Clinical significance of MLL-AF4 fusion transcript expression in the absence of a cytogenetically detectable $\mathrm{t}(4 ; 11)(\mathrm{q} 21 ; \mathrm{q} 23)$ chromosomal translocation. Blood (1998) 92:810-21.

44. Kowarz E, Dingermann T, Marschalek R. Do non-genomically encoded fusion transcripts cause recurrent chromosomal translocations? Cancers (Basel) (2012) 4:1036-49. doi:10.3390/cancers4041036

45. Kowarz E, Merkens J, Karas M, Dingermann T, Marschalek R. Premature transcript termination, trans-splicing and DNA repair: a vicious path to cancer Am J Blood Res (2011) 1:1-12.

46. Kuo YH, Landrette SF, Heilman SA, Perrat PN, Garrett L, Liu PP, et al Cbf beta-SMMHC induces distinct abnormal myeloid progenitors able to develop acute myeloid leukemia. Cancer Cell (2006) 9:57-68. doi:10.1016/j. ccr.2005.12.014 
47. Castilla LH, Garrett L, Adya N, Orlic D, Dutra A, Anderson S, et al. The fusion gene Cbfb-MYH11 blocks myeloid differentiation and predisposes mice to acute myelomonocytic leukaemia. Nat Genet (1999) 23:144-6. doi:10.1038/13776

48. Xue L, Pulikkan JA, Valk PJ, Castilla LH. NrasG12D oncoprotein inhibits apoptosis of preleukemic cells expressing Cbfbeta-SMMHC via activation of MEK/ERK axis. Blood (2014) 124:426-36. doi:10.1182/blood-2013$12-541730$

49. Kuo YH, Gerstein RM, Castilla LH. Cbfbeta-SMMHC impairs differentiation of common lymphoid progenitors and reveals an essential role for RUNX in early B-cell development. Blood (2008) 111:1543-51. doi:10.1182/ blood-2007-07-104422

50. Egawa T, Tillman RE, Naoe Y, Taniuchi I, Littman DR. The role of the Runx transcription factors in thymocyte differentiation and in homeostasis of naive T cells. J Exp Med (2007) 204:1945-57. doi:10.1084/jem.20070133

51. Growney JD, Shigematsu H, Li Z, Lee BH, Adelsperger J, Rowan R, et al. Loss of Runxl perturbs adult hematopoiesis and is associated with a myeloproliferative phenotype. Blood (2005) 106:494-502. doi:10.1182/blood-200408-3280

52. Seo W, Ikawa T, Kawamoto H, Taniuchi I. Runx1-Cbfbeta facilitates early B lymphocyte development by regulating expression of Ebf1. J Exp Med (2012) 209:1255-62. doi:10.1084/jem.20112745

53. Zhao L, Cannons JL, Anderson S, Kirby M, Xu L, Castilla LH, et al. CBFBMYH11 hinders early T-cell development and induces massive cell death in the thymus. Blood (2007) 109:3432-40. doi:10.1182/blood-2006-10051508

54. Chang H, Nayar R, Li D, Sutherland DR. Clonality analysis of cell lineages in acute myeloid leukemia with inversion 16. Cancer Genet Cytogenet (2005) 156:175-8. doi:10.1016/j.cancergencyto.2004.03.017

55. Cai Q, Jeannet R, Hua WK, Cook GJ, Zhang B, Qi J, et al. CBFbeta-SMMHC creates aberrant megakaryocyte-erythroid progenitors prone to leukemia initiation in mice. Blood (2016) 128:1503-15. doi:10.1182/blood-201601-693119

56. Hyde RK, Kamikubo Y, Anderson S, Kirby M, Alemu L, Zhao L, et al. Cbfb/ Runxl repression-independent blockage of differentiation and accumulation of Csf2rb-expressing cells by Cbfb-MYH11. Blood (2010) 115:1433-43. doi:10.1182/blood-2009-06-227413

57. Helbling D, Mueller BU, Timchenko NA, Schardt J, Eyer M, Betts DR, et al. CBFB-SMMHC is correlated with increased calreticulin expression and suppresses the granulocytic differentiation factor CEBPA in AML with inv(16). Blood (2005) 106:1369-75. doi:10.1182/blood-2004-11-4392

58. Imperato MR, Cauchy P, Obier N, Bonifer C. The RUNX1-PU.1 axis in the control of hematopoiesis. Int J Hematol (2015) 101:319-29. doi:10.1007/ s12185-015-1762-8

59. Pulikkan JA, Tenen DG, Behre G. C/EBPalpha deregulation as a paradigm for leukemogenesis. Leukemia (2017) 31:2279-85. doi:10.1038/leu. 2017.229

60. Zhang H, Alberich-Jorda M, Amabile G, Yang H, Staber PB, Di Ruscio A, et al. Sox4 is a key oncogenic target in C/EBPalpha mutant acute myeloid leukemia. Cancer Cell (2013) 24:575-88. doi:10.1016/j.ccr.2013.09.018

61. Cher CY, Leung GM, Au CH, Chan TL, Ma ES, Sim JP, et al. Next-generation sequencing with a myeloid gene panel in core-binding factor AML showed KIT activation loop and TET2 mutations predictive of outcome. Blood Cancer J (2016) 6:e442. doi:10.1038/bcj.2016.51

62. Duployez N, Marceau-Renaut A, Boissel N, Petit A, Bucci M, Geffroy S, et al. Comprehensive mutational profiling of core binding factor acute myeloid leukemia. Blood (2016) 127:2451-9. doi:10.1182/blood-2015-12-688705

63. Boissel N, Leroy H, Brethon B, Philippe N, de Botton S, Auvrignon A, et al. Incidence and prognostic impact of c-Kit, FLT3, and Ras gene mutations in core binding factor acute myeloid leukemia (CBF-AML). Leukemia (2006) 20:965-70. doi:10.1038/sj.leu.2404188

64. Haferlach C, Dicker F, Kohlmann A, Schindela S, Weiss T, Kern W, et al. AML with CBFB-MYH11 rearrangement demonstrate RAS pathway alterations in $92 \%$ of all cases including a high frequency of NF1 deletions. Leukemia (2010) 24:1065-9. doi:10.1038/leu.2010.22

65. Paschka P, Du J, Schlenk RF, Gaidzik VI, Bullinger L, Corbacioglu A, et al. Secondary genetic lesions in acute myeloid leukemia with inv(16) or $\mathrm{t}(16 ; 16)$ : a study of the German-Austrian AML Study Group (AMLSG). Blood (2013) 121:170-7. doi:10.1182/blood-2012-05-431486
66. Faber ZJ, Chen X, Gedman AL, Boggs K, Cheng J, Ma J, et al. The genomic landscape of core-binding factor acute myeloid leukemias. Nat Genet (2016) 48:1551-6. doi:10.1038/ng.3709

67. Will B, Vogler TO, Narayanagari S, Bartholdy B, Todorova TI, da Silva Ferreira M, et al. Minimal PU.1 reduction induces a preleukemic state and promotes development of acute myeloid leukemia. Nat Med (2015) 21:1172-81. doi:10.1038/ nm.3936

68. Kirstetter P, Schuster MB, Bereshchenko O, Moore S, Dvinge H, Kurz E, et al. Modeling of C/EBPalpha mutant acute myeloid leukemia reveals a common expression signature of committed myeloid leukemia-initiating cells. Cancer Cell (2008) 13:299-310. doi:10.1016/j.ccr.2008.02.008

69. Zhang P, Iwasaki-Arai J, Iwasaki H, Fenyus ML, Dayaram T, Owens BM, et al. Enhancement of hematopoietic stem cell repopulating capacity and self-renewal in the absence of the transcription factor C/EBP alpha. Immunity (2004) 21:853-63. doi:10.1016/j.immuni.2004.11.006

70. Ding L, Ley TJ, Larson DE, Miller CA, Koboldt DC, Welch JS, et al. Clonal evolution in relapsed acute myeloid leukaemia revealed by whole-genome sequencing. Nature (2012) 481:506-10. doi:10.1038/nature10738

71. Shlush LI, Zandi S, Mitchell A, Chen WC, Brandwein JM, Gupta V, et al. Identification of pre-leukaemic haematopoietic stem cells in acute leukaemia. Nature (2014) 506:328-33. doi:10.1038/nature13038

72. Farrar JE, Schuback HL, Ries RE, Wai D, Hampton OA, Trevino LR, et al. Genomic profiling of pediatric acute myeloid leukemia reveals a changing mutational landscape from disease diagnosis to relapse. Cancer Res (2016) 76:2197-205. doi:10.1158/0008-5472.CAN-15-1015

73. Sood R, Hansen NF, Donovan FX, Carrington B, Bucci D, Maskeri B, et al. Somatic mutational landscape of AML with $\operatorname{inv}(16)$ or $t(8 ; 21)$ identifies patterns of clonal evolution in relapse leukemia. Leukemia (2016) 30:501-4. doi:10.1038/leu.2015.141

74. Kim HG, Kojima K, Swindle CS, Cotta CV, Huo Y, Reddy V, et al. FLT3ITD cooperates with inv(16) to promote progression to acute myeloid leukemia. Blood (2008) 111:1567-74. doi:10.1182/blood-2006-06-030312

75. Zhao L, Melenhorst JJ, Alemu L, Kirby M, Anderson S, Kench M, et al. KIT with D816 mutations cooperates with CBFB-MYH11 for leukemogenesis in mice. Blood (2012) 119:1511-21. doi:10.1182/blood-2011-02-338210

76. Enright H, Weisdorf D, Peterson L, Rydell RE, Kaplan ME, Arthur DC. Inversion of chromosome 16 and dysplastic eosinophils in accelerated phase of chronic myeloid leukemia. Leukemia (1992) 6:381-4.

77. Han E, Lee H, Kim M, Kim Y, Han K, Lee SE, et al. Characteristics of hematologic malignancies with coexisting $\mathrm{t}(9 ; 22)$ and inv(16) chromosomal abnormalities. Blood Res (2014) 49:22-8. doi:10.5045/br.2014.49.1.22

78. Salem A, Loghavi S, Tang G, Huh YO, Jabbour EJ, Kantarjian H, et al. Myeloid neoplasms with concurrent BCR-ABL1 and CBFB rearrangements: a series of 10 cases of a clinically aggressive neoplasm. Am J Hematol (2017) 92:520-8. doi:10.1002/ajh.24710

79. Secker-Walker LM, Morgan GJ, Min T, Swansbury GJ, Craig J, Yamada T, et al. Inversion of chromosome 16 with the Philadelphia chromosome in acute myelomonocytic leukemia with eosinophilia. Report of two cases. Cancer Genet Cytogenet (1992) 58:29-34. doi:10.1016/0165-4608(92)90129-V

80. Wu Y, Slovak ML, Snyder DS, Arber DA. Coexistence of inversion 16 and the Philadelphia chromosome in acute and chronic myeloid leukemias: report of six cases and review of literature. Am J Clin Pathol (2006) 125:260-6. doi:10.1309/F0MX5CL8CEDY3W86

81. Andersen MK, Larson RA, Mauritzson N, Schnittger S, Jhanwar SC, PedersenBjergaard J. Balanced chromosome abnormalities inv(16) and $t(15 ; 17)$ in therapy-related myelodysplastic syndromes and acute leukemia: report from an international workshop. Genes Chromosomes Cancer (2002) 33:395-400. doi: $10.1002 /$ gcc. 10043

Conflict of Interest Statement: The authors declare that the research was conducted in the absence of any commercial or financial relationships that could be construed as a potential conflict of interest.

Copyright (c) 2018 Pulikkan and Castilla. This is an open-access article distributed under the terms of the Creative Commons Attribution License (CC BY). The use, distribution or reproduction in other forums is permitted, provided the original author(s) and the copyright owner are credited and that the original publication in this journal is cited, in accordance with accepted academic practice. No use, distribution or reproduction is permitted which does not comply with these terms. 